\title{
Medical Pluralism among the Tharus of Nepal: Legitimacy, Hierarchy and State Policy
}

Bamdev Subedi

\begin{abstract}
This paper offers an understanding of medical pluralism as practiced among the Tharus of Nepal, and makes a discussion on the indigenous medicine in relation to the state health policy and the ambivalence that exists regarding official recognition of indigenous healers. Field data were collected from a village cluster of Dang district following qualitative methods: observation of healing sessions, interview with healers, patients, and key informants. Tharu healing tradition consists of three main practices: shamanic, herbal, and midwifery; practiced mainly by three types of healers: guruwa, baidawa, and surenya who employ three major strategies of healing: mantra, medicine and massage. The knowledge of healing mantras, use of local herbal medicine, and traditional midwifery and massage are the most important features of the Tharu's indigenous healing practices. Such practices, along with those of co-inhabited non-Tharu healers and healing practices form the universe of local folk medicine. The folk medicine, which represents an oral tradition, co-exists along with scholarly traditional medicine and biomedicine. In terms of official recognition and support, biomedicine is on the top followed by scholarly traditional medicine and folk medicine falls at the bottom of the hierarchy. The scope of medical pluralism has been widened with the inclusion of scholarly traditional medicine in the official health care system. However, many of the indigenous traditional medicines that indigenous ethnic communities continue to practice still fall outside the purview of state regulation. The legitimacy of indigenous healers remains in question. An expression of sceptical and ambivalence attitudes towards indigenous healers has been reflected in the policy and planning documents. There has been an insignificant and inconsistent efforts to link indigenous healers with the official health care system and a hesitation to legitimize indigenous traditional medicine. A serious reflection is needed to move ahead from this ambivalence and inaction towards a more inclusive and democratic medical pluralism.
\end{abstract}

Keywords: medical pluralism, traditional healers, legitimacy, health policy, Tharus of Nepal

\section{Introduction}

South Asia is rich in terms of medical diversity. The richness is reflected in the therapeutic traditions among the ethnic communities living in the land of cultural and geographical diversity. South Asian medical pluralism is unique in that diverse forms of indigenous medicines coexist along with scholarly, codified or officially sanctioned traditional medicine, and biomedicine. Though the scope of medical pluralism has been widened with the inclusion of scholarly traditional medicine in the national health care system, the indigenous forms of medicines that ethnic communities continue to practice fall outside the purview of state regulation. The indigenous medicine which is explained by the terms of folk, popular, non-codified traditional medicine receives little policy attention despite its immense scope and coverage. Though indigenous healers serve as immediate source of care, policy documents tacitly express a hesitation to provide them with a legitimate space in the health care system. This paper offers an understanding of medical pluralism as practiced among the Tharus of Nepal and makes a discussion on the indigenous medicine in relation to the state health policy and the ambivalence that exists regarding official recognition of indigenous healers.

The concept of medical pluralism has been used not only to refer to a situation where different systems of medicine co-exist but also to refer to the pluralism within a particular system giving access to various levels and types of care (Hyma \& Ramesh, 1994; Minocha, 1980). People make use of diverse therapeutic options, often using one option as an alternate of or complement to another or combine treatment from different traditions (Kalpagam, 2012). People are pragmatic in that they use different forms of medicine to meet their health care needs (Bode \& Hariramamurthi, 2014). The poor as well as well- off sections of both developed and developing world practice medical pluralism (Priya, 2012).

Scholars have well documented pluralistic health care practices of the people of Nepal (Durkin-Longley, 1984, Subedi, 1989; Subedi, 1992; Subedi, 2003; Subedi, 2016b). The pluralistic health care practices are common even among the indigenous ethnic communities. With the changes in perceptions and practices particularly induced by socio-economic changes, interactions with and interventions by outside societies, and state intervention in health these communities are also found open to the options

This work is licensed under the Creative Commons $@$ Bamdev Subedi

Bamdev Subedi: PhD from JNU, New Delhi, and independent consultant

Email: bamdevsubedi@gmail.com/https://orcid.org/0000-0002-6843-6412 
available. Indigenous ethnic communities, including the Tharus of Nepal, also practice some degree of pluralism as they seek care not only from the indigenous healers but also from medical practitioners of co-existing medical systems (Parker,1988; Shafey, 1997).

Tharus are one of the marginalized ${ }^{1}$ ethnic groups ${ }^{2}$ of Nepal. They are the inhabitants of Tarai region ${ }^{3}$ and are also found across the Indo-Nepal border, in areas of Uttarakhand, Uttar Pradesh (UP) and Bihar and are also recognized as Schedule Tribe in India (Maiti, 2001). Tharus are described as one of the early settlers of the Tarai region and they are also known for their natural resistance to malaria (Regmi,1999) developed in course of time living in and around the malaria infested forest. When malaria was controlled the area attracted non-Tharu people, especially from the Hill region. Now, the district has a mixed population. However, Tharus are still in majority among the co-inhabited several other caste/ethnic communities ${ }^{4}$. Tharus are divided into sub-groups such as Rana, Katharia, Dangoura, Kochila, Mech (Rajaure, 1981) and with some variation Tharu language is spoken as their mother tongue which is much influenced by and structurally closer to Nepali language (McDonaugh, 1989 p. 193). Some of the early inhabitants from non-Tharu community also speak Tharu to communicate with them. However, it is the Nepali language which is used as lingua franca for day-to-day communication. Their religion consists of a mix of shamanistic and animistic religious beliefs and practices with an influence of the Hindu religion (Rajaure, 1982; Regmi, 1999). They also worship Hindu God and Goddess as well as their clan deities. Their main occupation is agriculture supplemented by animal husbandry.

The Tharus have experienced an unprecedented change in their life since the last few decades (Guneratne, 2010). There are visible changes in many aspects of their lives. Now, a large number of youth go abroad, especially to Golf countries, Malaysia and Korea for an employment opportunity. The expansion of markets, transport and communication, education and awareness, increased

1 There are 59 adibasi janajati (indigenous nationalities) notified by the government of Nepal. NFDIN (2003) has classified indigenous nationalities into five categories: Endangered, Highly Marginalized, Marginalized, Disadvantaged and Advanced Groups. Tharus have been classified as Marginalized group. Adibasi janajati constitute more than one-third of the total population of Nepal.

2. Nepalese scholars prefer 'ethnic groups' over the 'tribal people' (Dahal, 2012 , p.139). Officially they are called indigenous nationality, defined as "a tribe or community having its own language and traditional rites and customs, distinct cultural identity, distinct social structure and written or unwritten history" (NFDIN, 2003, p. 32).

3. Nepal is divided into three geographical regions stretched from east to west: Mountain, Hill, and Tarai (Plain). To the north, lies the Mountain region which houses some of the highest peaks of the world, including the Mount Everest. To the south, lies Tarai region which comprises plain areas expanded up to the Indo-Nepal border, and in between lies Hill region which comprises hilly areas and some of the beautiful valleys. Tharus are the inhabitants of Tarai region

4. According to the 2011 census, Tharu constitute 29.5 percent of the total population of Dang district (i.e.552583) (CBS, 2014b). Nationally, they are the fourth largest caste/ethnic group in terms of both population and language. interaction with non-Tharu communities, and increased exposure to the outside world, has brought changes in food practices, marriage, housing, fashion, lifestyles and worldviews. The expansion of health care services, both public and private, has added to their therapeutic choice and options.

While explaining the organization of Nepal's health and medical system NESAC (1998, p. 60) highlighted (i) home-based system, (ii) the traditional faith healing based system, (iii) the ayurvedic, homeopathic and unani systems, and (iv) the modern allopathic system. A little modification can be made to explain the diversity of medical tradition in Nepal. Home-based system refers to home remedies which "span[s] from divination to faith healing and the use of local herbs" (NESAC, 1998). The home-based system is close to what Kleinman (1980) calls 'popular sector' which comes handy for a range of ailments. Sometimes, people are forced to rely on home remedies because official health care services are of limited access, of low quality, and of high costs. Varieties of vegetables, spices, and herbs are used and diet plan followed at the household level. For minor illnesses and injuries, first attempt is home remedy. They resort to the local healers or medical practitioners when home remedies fail but it may continue during and even after the medical consultations.

Folk medicine represents the oral, non-textual, noncodified, non-institutionalized, popular forms of traditional medicine. This is a form of indigenous traditional medicine which includes indigenous health knowledge and practices. This is the traditional medicine most popular in Nepal. A large section of rural population relies on indigenous traditional healers which can be grouped into three categories (i) shamanic, spiritual and faith healers known as dhami-jhankri (shamans), jhar-phuke (faith healer who sweep down and blow out evil spirits using small hand broom and healing mantras), janne manchhe (literally knowledgeable person), pundit (the Hindu religious, spiritual and faith healers who perform various ritualistic healing, to appease deities, and offer tikas, to be put on forehead) and jyotish (astrologers who read kundali, the birth-chart, graha-dasha, the spoiled planet-star, and recommend for grah-shanti, the ritual for appeasing of planet Gods such as Sani- the Saturn, wearing of ring with specific stones and amulets), provide faith healing, (ii) herbal healers (known as vaidya, hakim) who provide herbal healing and some of them provide specialist care for jaundice, gastritis, sprain, injuries, fractures, snake-bites and so on (iii) the traditional midwives (known as sudeni) who provide traditional midwifery, post-delivery care and massage.

Scholarly traditional medicine refers to the textual, codified and institutionalized tradition of traditional medicines and are "based on sound theories and principles"(Gewali, 2008) such as ayurveda, unani, homeopathy, sowa rigpa (Tibetan systems), yoga and naturopathy. Ayurveda has a leading status among the traditional medicine in Nepal. There are many ayurveda hospitals, health centers and dispensaries. However, there is only one homeopathy and one unani hospital run 
by government sector. Parallelly, the private hospitals and clinics also provide the services of ayurveda, unani, homeopathy, acupuncture, naturopathy, and sowa rigpa. Besides, there are several yoga and meditation centers emerged with "new religious movements and therapists" (Toffin, 2016).

Biomedicine which is invariably referred as 'western medicine', 'modern medicine', 'scientific medicine', 'allopathic medicine', 'cosmopolitan medicine' is the most dominant system in the present day world. Health care system in Nepal is mainly based on biomedicine which has a predominant status with its vast network of hospitals, health centers/posts, medical colleges and nursing schools, clinics, pharmacies and a wide range of practitioners. Health care services are provided by both public and private sectorsand in both sector biomedicine dominates. State resources are largely directed to the delivery of biomedicine-based health care services, biomedical education and research. As in many societies, biomedicine has become a dominant system in Nepal which can be compared with a large tree under which the presence of other forms of medicines look as if they are shrubs and herbs (Subedi, 2016b).

\section{Methods}

This paper draws from a qualitative study which was conducted among the Tharus of Dang, a district of Nepal, which lies approximately $450 \mathrm{~km}$ south-west of Kathmandu. Field data were collected from Saudiyar, following qualitative methods: observation of illness episodes followed by interview with the healers and the patients. Saudiyar is a village cluster located about eight kilometers south-west of Ghorahi, the nearest city. A dozen of caste/ethnic groups live in the area but Tharus comprise 53.2 percent of the total population (i.e.12101) (CBS, 2014b). The healers' information was collected with the help community people. A total of 101 healers identified, of them 65 were from Tharu community and of them 18 healers were purposively selected and approached making home visits. They were briefed about the study purpose and requested for participation. All of them agreed to participate in the study. The interview was conducted in Nepali and noted down and translated into English. Of the 18 healers contacted for interview eight were guruwas, five were baidawas and five were surenyas. Most of them were elderly (average age was 60), highly experienced (served 22 years in an average), had learned the healing knowledge and skills in families from elder members or from the senior healers. Half of them were literate and one third of them hold multiple positions in community based organizations such as aguwa, a village leader who looks after the irrigation system and makes decision in many matters. They were invited as guests in local level programs, formal meetings and village functions including those of rite-de-passage events.

Some of the healing sessions were observed and 27 patients, who were contacted while they were consulting healers were interviewed. The selection was made on the basis of their availability. Most of them were contacted at the healing sessions and interviewed later at their convenience. Often patients were found at the healers' home but some healers were also found at the patients' home. Those were visited accompanying with the healers. Of the 27 patients contacted for interview, 14 were with guruwas, ten with baidawas and three with surenyas. Among these patients 23 were from the same area and four were from distant villages, 21 were from the Tharu (and six were from non- Tharu) communities, 15 were female (and 12 were male). The patients were comparatively younger (average age was 27) and educated (13 of them had education up to $10^{\text {th }}$ grade). Like those of healers, their main occupation was agriculture. Additionally, nine key informants were interviewed and three group interactions were conducted with female health volunteers, school teachers and cooperative members. The observation and interviews were conducted after seeking their verbal consent. The collected data were analyzed manually and findings were presented in narrative forms.

\section{Findings and Discussions}

\section{The Tharu healers and the healing practices}

There are various types of healers who have distinct healing knowledge and skills and follow different methods of healing. The Tharu healers are generally known as guruwa, baidawa and surenya. In some places guruwa is pronounced as gurau, baidawa as vaiduwa (seems derived from ayurvedic vaidya), surenya as sorheniya (and sudeni in Nepali language). I follow what is mostly pronounced in the study area (See Rajaure, 1981a; 1981b; Shafey, 1997; Adhikari, 2006; Dahit, 2008).

\section{Guruwa:}

The healers who use mantras and perform therapeutic rituals are known as guruwas. The guruwas are shamanic, spiritual and faith healers, and also play a customary priestly role to perform various rites and rituals and worship various types of deities for the wellbeing of an individual, family and community. It is said that there are more than 200 types of mantras, which are considered important to deal with a range of health problems mostly of psychosocial nature. The mantras are considered powerful because these mantras contain the qualities of appeasing the angry deities and driving out bhut-pret, the evil spirits. Guruwas do not go into trance like those of dhami-jhankris in their healing sessions but they go mass trance in some of the ritualistic events.

Guruwas follow certain methods of diagnosis and treatment such as pati baithna, in which they recite mantra while swinging earthen saucer with a burning cotton wick, jhar-phuk, in which they sweep down and blow out the evil spirits using a small hand broom along with healing mantra, achheta herna, in which they randomly take a few rice grain and associate the odd and even numbers of grains with possible causes of illness, pani phukna in which a guruwa blows mantra into a glass of water mixed with a little turmeric powder or firewood ash and gives 
patient to drink, bhakal chadhaina in which they offer birds and animals to the God and Goddess of a particular religious shrine, buti badhna in which they make and give a jantar (an amulet) to wear. They also check the physical conditions, read the pulse and give some crude herbs as medicines. There were patients who had problems of nightmare, evil spirit, headache, heart palpitation, sudden vomiting, dizziness and soul lose who had come to visit them.

Guruwas go through a ritual called baan chirna in which they make small cuts on some of the body parts such as forehead, tongue, shoulder, chest, knees and toes to offer blood to their deities annually in Dashain festival. They enjoy a high esteem compared to baidawas and surenyas. However, there are five categories of guruwas: general guruwa, who can be found in large numbers in a Tharu villages; kesauka guruwa who assists senior guruwas in their priestly and therapeutic rituals; dharharya guruwa who is a guruwa appointed by senior guruwa for a temporary task; ghar-guruwa, who performs household level priestly rituals such as lausari, a ritual performed twice a year in the family for the health and wellbeing of the children and family members and desh-bandhya guruwa who performs community level rituals such as gurrai, a ritualistic event performed twice a year at the village shrine for the health and wellbeing of the village. Ghar-guruwas and deshbandhaya guruwas enjoy the highest esteem among the guruwas. The position of desh-bandhya and ghar-guruwa is hereditary and they get free labor from their clientele at the time of planting or harvesting crops. In the past, some of them were provided with laal mohar (royal edicts), an authority to perform healing rituals to protect the village from evil spirits, disease and epidemics, and collect local revenues (Guneratne, 2010; Rajaure,1982)

\section{Baidawa}

The herbal healers and specialists who deal with joints dislocation, bone fracture, jaundice and stomach problems are called baidawas. Baidawas do not involve in priestly work and do not undergo the ritual of baan chirna. Unlike the guruwas, who are known for their knowledge of mantras and ritualistic healing practices, baidawas are known for the knowledge of jadi-buti (roots and plants), animal products and mineral substances and herb-based healing practices. They collect and process jadi-buti and dispense them as medicines. Among the patients contacted at the baidawas had problems of swelled leg, thorn prick, stomach ache, sukenas (wasting), pinas (nasal problem), putrena (dislocation of stomach), joints pain, and alcoholic sleeplessness. The baidawas usually observe and examine affected parts, ask about the problem and read pulse rate for diagnosis. They give herbal medicine and suggest what to eat and what not to eat according to the types of illness. Some of them are particularly known for bone setting, snake bite healing, abdominal massage, toothache, joints pain and jaundice.

\section{Surenya}

The women who assist in childbirth and provide pre-and post delivery care are known as surenyas. They also provide midwifery and massage services to the mother and newborn and other women and children in need. All the villagers seek their services and there is no substitute for the kind of services they provide. They are called upon not only to provide massage during the postpartum period but also to help in bathing, cleaning, washing, cooking and other household chores. In case of delivery, their service generally starts before the last few days of childbirth and continues till the eleventh day after birth, when the naming ritual performed. At present surenyas are accompanying women to hospitals because the government is promoting institutional deliveries by providing cash incentives to mothers. However, massage service after delivery is considered essential and surenyas continue their services once women are discharged from the hospital. Their services are highly demanded from both Tharu and non-Tharu families in the village. They rub and knead parts of the body with treated mustard oil (or butter, ghee, homemade wine, turmeric and herbs) manually to help at times of pain, weakness and fatigue. Massage is an important part of indigenous healing practices and massage as family tradition exists in every household. Surenyas also give suggestions about beneficial and harmful food for women during the pregnancy, postpartum and lactating periods, taking seasonal changes into consideration.

\section{The healers and health care services in the area}

Similar types of healers known as dhami-jhankri, vaidya and sudeni were found among the co-inhabited non-Tharu communities. Besides, vender herbalists, who come from Mountain region of Nepal and also from UP and Bihar of India, sell various jadi-buti (herbal medicines) and provide treatments to the patients specially those who are suffering from chronic problems. Both the Tharu and non-Tharu healers and healing practices constitute the local folk medicine. There is a government health post and half a dozen of private pharmacies in the study area. These pharmacies keep biomedical drugs and some popular ayurvedic products. At the district level, there are two government hospitals, four primary health care centers, 36 health posts, an ayurvedic hospital, three ayurvedic dispensaries, and two eye hospitals. There are several privately run biomedical hospitals, clinics and pharmacies, a few dental clinics, eye care center, ayurveda, homeopathy and acupuncture clinics, yoga and meditation centers, and a ceragem centers in Ghorahi.

\section{The patients and the choice of healers}

The patients had diverse illness problems, of minor or major, acute or chronic nature. They gave different reasons for the choice of a particular healer. For example, a woman who had problem of nightmare said, "In hospital they can laugh at you when you report them such problems." She was suffering from nightmare, having a dream of bloody fight repeatedly in the last few days. A school teacher whose child had problem of sukenas (having stunted 
and wasted child) said, "I have come here to consult him (name of the healer) because one of my friends suggested when the medicine I got from the hospitals did not show an effect." A woman who was contacted when she was consulting a baidawa for the treatment of swelled leg of her seven year old son said, "You need at least a thousand rupees when you go to hospital but here (at the baidawa's home) you don't need that much... fifty or hundred rupees to the maximum." This shows that the patients compare the service and cost with the types of illness. This also indicates that they also take recourse to the official medicines in many instances. To avoid long queues and for quick treatment most of the patient resort to private hospitals or clinics where they pay fees for consultation, diagnosis and drugs. A participant with baby child replied, "When your baby falls ill how long you can wait to see a doctor? We go to the private clinics when we are in a hurry. We don't have to wait long and doctors in private clinics give a little more time than in the government hospital."

On the question, "is this your first time with this healer?", only eight patients responded affirmatively. Most of them had visited earlier at least twice or thrice. The main reasons for choosing particular healer was because they have faith on them that they can help in their problems. Some of them were quite confident about their selection. A patient said, "I know he can provide good care for stomach problem. He has treated so many people with such problem." More than two third of the patients expressed satisfaction with the services provided by healers and a little less than one third patients wanted to have their say later. They were satisfied because they believed in the capacities of the healers. Here, the voluntary and helpful nature of the healers also appreciated. One of the elderly patients praised, "He came at midnight and saved my life like a God. There was no other person to treat snake bite at that time. He is always ready... not greedy... asks for nothing and comes when called even in the midnight." When asked, the same healer proudly said, "I have made no one to mourn. God has blessed me save life of everyone I treat." About the snake bite, other participants also expressed their faith in the village healers, "Anything can happen when you choose to go to hospital but here nobody has died, because of snake bites."

Some of the people expressed different opinions on the indigenous healers and healing practices. In an interaction with cooperative members, a participant said, "I don't believe that they are all good. Some are good [experienced and honest] but some are thug (quack)." Another participant added, 'Some guruwas take patients' illness as a source of food and drink. First they say, 'mai chokha dem, mai biruwa kai dem' (I have a cure, I can treat your illness) because they want to be served with good foods and drinks for few more days and when the patient's condition deteriorates further, they say aspatal le cholo (rush to hospital)." This delays the treatment. A participant, however, rectified, 'You will find only a few such type of guruwas, who might be greedy. We do not go to hospital for laagu-bhagu (caught by malevolent spirit) and many of us are consulting these healers at least for manako shanti (mental peace and confidence)."

\section{Perception and patterns of resort}

Tharus believe that an individual falls ill not only because of rog (disease) but also because of laagu-bhagu. By rog they mean disease which a person gets from various reasons such as contacting a person with disease, having stale or unhygienic food, contaminated water, changes in weather condition and imbalance of hot-cold food. Some of the patients viewed that the excessive use of chemical fertilizers, insecticides and pesticide also cause health problems. By laagu-bhagu they mean illness caused by evil spirits and wrath of deity. They usually visit guruwa when they suspect of laagu-bhagu and baidawas or medical practitioners when they suspect of rog (disease) and for physical injuries. They know whom to consult for what type of problems. When they are uncertain about the cause of an illness they resort to the healers as well as to the medical practitioner simultaneously. A general rule is that for illnesses caused by evil spirits and wrath of deity shamanic healer is the best choice, for physical problems and injuries herbal healer or medical practitioners and for birth assistance or pre- and postpartum care and massage traditional midwives. This partly tells how they select the healers and what the logic behind their selection is.

The villagers do not care much about the bearable amount of pain such as headache, stomach pain and back pain, running nose, short fever, etc. They do not seek treatment for some time with the hope that body will heal on its own. When they feel a need, they try by themselves or seek help from their family members, friends and neighbors and if that does not work they visit local healers, health post or private pharmacies or they may decide to go to hospital. Choice is made based on the the experience of family, relatives and neighbors, the familiarity with the healers or practitioners, the type and severity of the illness, and the quality and cost of care. The treatment seeking order, thus, starts from home remedies then moves to the local healers and hospital as the last resort. They think that it is not wise to go to the distance hospital without consulting the local healers. They argue, "What is wrong showing once to a local healer before going to city hospital." In many cases, they want to be assured that there is no supernatural elements behind an illness. The healers also suggest patients go to hospitals if the illness is not likely to be treated by them. The healers are the first point of contact for many illnesses and they are consulted by both Tharu and non-Tharu, educated and uneducated, rich and poor patients. In most cases, general resort pattern follows home remedies to healers (to/or health practitioner) to hospitals. Sometimes they come back from hospitals and again consult these healers which is explained as counteracculturative pattern (Schwartz, 1969).

\section{Changes in perceptions and practices}

The study participants gave many instances of changing perceptions and practices. Some of them took positively to the changes but most of them seemed worry about the 
changes that have been taking place in agriculture, food practices, availability of medicinal herbs, and deteriorated health traditions. Some also pointed to a declining role of the indigenous healers and unwillingness of youth to learn and practice. They said that comparatively fewer people visit healers and even if they visit, the healers also suggest them to visit medical practitioners at hospitals. Now surenyas are called less in childbirth and their role has shrunk to post delivery care and massage. The baidawas have started selling locally manufactured herbal drugs rather than collecting and preparing on their own. Some healers have started to charge money for their services and medicine but they are criticized for charging. This points to a moral dilemma, a change in the healers' practices, a decline in the enthusiasm among the local healers and an increase in the use of other forms of medicine. A key informant from District Public Health Office admitted, "It is true that people haven't stopped visiting local healers because they treat some problems effectively. Sometimes the (local) doctors and their family members also visit them for certain kind of illnesses. Nowadays, hospitals get more patients because people are increasingly coming to the hospitals."

Some participants, especially those of educated youths tend to favor herbal healing, midwifery and massage because they express doubt over the power of mantras and the relevance of shamanic healing practices. Some of them even questioned the usefulness of medicinal herbs, "Disease cannot be cured by eating jhar-paat (grass of no use)." The intention was to show no difference between jadi-buti and jhar-paat. One of the key informants, who was a local leader, argued for the importance of herbs, "These youth do not understand the importance of herbs; they cannot distinguish between $g u$ (human feces) and gobar (cow dung). There is a difference but they don't know. This is similar to jannelai srikhanda, najannelai khupako bid, a proverb that tells the difference between who know and who do not know the value of an item."

This indicates to a change in the perception, a loss of traditional herbal knowledge, a need to seek scientific rational for healing practices. Some of them have a tendency to be modern, scientific and rational by not giving importance to anything traditional, unscientific and irrational (Pigg, 1996). This is also reflected in the health seeking behavior of the people. However, there are certain people who say that they do not believe in shamanic healing because it is not scientific, but if observed closely they can be found visiting shamanic healers. If asked, they justify the visit saying this and that. This kind of behavior termed as "ambivalence of modernity" (Pigg, 1996, p. 199) can be observed in the villages. And it is also true that when nothing cures and problem persists people show willingness to try anything. A participant justified the importance of these healers, "There may be good doctors in faraway cities. Not those doctors but these healers come for our help when we are in need."

Though there are arguments and counter arguments about the relevance and usefulness of the indigenous healers, they still play an important role in health and illness. One of the reasons why people turn to these healers is because of the kind of service which other practitioners cannot provide and another reason is that, the healing practices closely correspond to the patient's beliefs and perceptions. The challenge is to ensure a good quality care from these healers. To make these healers better serve the community, an effort should be made to improve upon their therapeutic knowledge and equip them with necessary skills. The local healers can contribute to the public health programs when they are mobilized with necessary skills. They were appreciated for providing referral support to biomedical health care program (See Oswald, 1983). However, no efforts have been made to recognize their knowledge and practices, enhance their capacities and integrate them into the formal health care system.

The role of the traditional healers to improve the health of the community and importance to integrate these healers in the national health system was highlighted in the Alma- Ata Conference (WHO \& UNICEF, 1978). It was highlighted that with recognition, integration and necessary skill development these healers can contribute to the primary health care. As the state involvement in both financing and provisioning is poor and out-ofpocket expenditure constitutes a larger part of heath financing (Yazbeck \& Peters, 2003), from the public health perspective mobilization of local healers would be an affordable option.

\section{Folk medicine at the bottom of the hierarchy}

People have been encouraged to practice medical pluralism with an official inclusion of scholarly traditional medicine in the national health care system. However, a hierarchy of medicine exists where biomedicine is on the top followed by scholarly traditional medicine and at the bottom falls the folk medicine. In this hierarchy, folk medicine is subordinated to traditional medicine and traditional medicine is subordinated to biomedicine (Leslie, 1988). Looking at the level of availability, accessibility, utilization patterns, official legitimacy, and power relationships the kind of medical pluralism has been characterized as 'plural but not pluralistic' (Baer, Singer, $\&$ Susser 2003) 'reduced and simplistic'(Pordie, 2007) 'highly restricted'(Prasad, 2007), 'syndicated' , 'forced' (Sen, Iyer, \& George, 2007), 'imposed' (Albert et al., 2015), 'illusory' (Han, 2002) 'exclusionary' (Attewell et al., 2012) and 'undemocratic' (Priya, 2012). By definition, medical pluralism entails greater choice and greater options for everyone (Kalpagam, 2012; Prasad, 2007). However, in the hierarchical society, choices are often limited to the people at the bottom and when state favors one medical system over others there cannot be greater choice and options (Bode, 2011 p. 17).

The scholars have highlighted the importance of folk or indigenous traditional medicine in meeting wide range of health care needs of the people and the role of indigenous healers in providing physical, social, mental and spiritual health (Subedi, 1989, 2003). Folk medicine is characterized as culturally acceptable, physically accessible and economically affordable. Folk 
medicine serves as 'primary medicines' because till now "biomedical health-care services are extremely limited and are largely situated in urban settings" (Tamang \& Broom, 2010, p. 328). Even where biomedical healthcare services are available, the popularity, persistence and pervasiveness of folk or indigenous traditional medicine is high.. However, the traditional healers are losing their legitimacy with new policy developments. For instance, when Ayurveda Medical Council Act 1988 imposed a provision of registration giving one year's time for those who were of 50 years and above and have been practicing herb-based medicine since the last three generations, many left unregistered (See Nepal Law Commission, 1988)

The indigenous healers and healing practices have got scant attention in health policy and development plans. Fulfillment of basic minimum needs was the priority of the Sixth Plan and training program was planned to improve the services of the local healers (vaidya and jhankri) to provide minimum health services to the rural populations (NPC, 1980). The Eighth Plan also stated to provide appropriate training to traditional healers including birth attendants and mobilize them in disseminating information pertaining to health, nutrition and family planning (NPC, 1993). The Ninth Plan aimed to encourage about 800,000 dhami, jhankri, lama, and vaidya to provide health services (NPC, 1997). National Ayurveda Health Policy 1996 was to provide training to the traditional healers on the production, collection, protection and usage of medicinal herbs to mobilize people's participation in ayurveda health services (MoHP, 1996). The policy asserted to organize campaign to protect and keep intact the relevance of indigenous healers' knowledge. Official documents accept the omnipresence of traditional healers and their significant role in providing health care services to the masses and at the same time, they also acknowledge the insignificant support of the state to link them with the public health system (NESAC, 1998, p. 60) (emphasis mine). The MoHP annual report also begins with an affirmation of the significant role played by the traditional healers in the health care sector of Nepal (MoHP, 2012). Nepal health sector strategy (2015-2020) also recognizes the practices of gurau and prevalence of traditional faith healers such as dhami, jhankri, guvaju, jharphuke etc. in many communities and shows a need of stocktaking and mainstreaming of these practices. However, the recent national health policies tend to disregard the relevance of traditional healers at the present time (MoHP 2014, 2017). This shows the sceptical and ambivalence attitudes towards traditional healers. On the one hand, official documents acknowledge the wide existence and use of traditional healers for primary health care showing their importance, on the other, no effort has been made to recognize them and legitimize their practices.

One of the state policies is to ensure access to high quality health care for all. This also means quality care of all forms of medicine. However, the health care resources have been directed to the expansion of biomedicine-based health care system. In terms of official support and provisioning of the services even scholarly traditional medicines have not got their due share. It would be ridiculous when we put water into one plant and complain undergrowth of another. If we expect a real growth of traditional medicine, both of its popular and scholarly forms, we need to put some water into them. If we want to improve people's health, we need to invest in the indigenous medicine which are close to them and which they have been utilizing. It is simply logical that only with strong foundation whole building stands strong. We need to enhance indigenous knowledge and empower indigenous people. The indigenous people have experienced a change in their life and they express a loss of experiential health (Subedi, 2016a) They are doing whatever they can for their health and wellbeing. If anything outside intervention is intended that should not disempower them.

\section{Conclusion}

The medical pluralism as practiced among the Tharus signals to an increased use of other forms of medicine and a weakened state of indigenous healing practices. There is no dearth of narratives which explain indigenous healing practices as vanishing, disappearing, dying, being displaced or becoming extinct. However, these practices still hold a strength because of the persistent use among rural ethnic communities.

The sceptical and ambivalence attitudes towards indigenous healer have been reflected in the policy and planning documents. There has been an insignificant and inconsistent efforts to link indigenous healers with the health care system. There has been a hesitation to legitimize indigenous traditional medicine and to provide due space to the indigenous healers. Their legal status remains in question even though they are the most trusted, most intimate and immediate source of health care for many.

A sort of mismatch can be observed between people's preferences and policymakers priorities and also between what state commits to do in its policy documents and what actually it does. The policy was to encourage traditional healers and develop, protect and expand ayurveda and other alternative systems. But in practice what is being encouraged, developed, protected and expanded needs no further clarification. The policy has remained either silent or has spoken an ambivalent language when it comes to indigenous traditional medicine. A serious reflection is needed to move ahead from this ambivalence and inaction towards a more inclusive and democratic medical pluralism.

\section{Acknowledgement:}

The earlier version of this paper entitled as 'Understanding the way medical pluralism is practiced: Looking through the eyes of the Tharus' was presented at the international seminar on 'Indian Medicine between State and Village' organized by International Institute for Asian Studies held on 23-24 June 2016 at Leiden, the Netherlands. I am indebted to Sunita Reddy, Helen Lambert, Maarten Bode and two anonymous reviewers for their comments which greatly helped to restructure the paper in this form. 


\section{Funding:}

I have received no financial support for this work.

\section{Ethical approval for the research:}

Not applicable.

\section{Conflict of Interest:}

I declare no conflict of interest.

Ethical Conduct of Research:

I declare that this research has been conducted ethically.

\section{References}

Adhikari, K. (2006). Indigenous healing practices among tharus of amrai village in dang. Education and Development, 22(Special issue), 106-116.

Albert, S., Nongrum, M., Webb, E. L., Porter, J. D., \& Kharkongor, G. C. (2015). Medical pluralism among indigenous peoples in northeast india-implications for health policy. Tropical Medicine and International Health, 20(7), 952-960.

Attewell, G., Hardiman, D., Lambert, H., \& Mukharji, P. B. (2012). Agendas. In Medical Marginality in South Asia: Situating Subaltern Therapeutics. David Hardiman and Projit Bihari Mukharji, eds. Routledge.

Baer, H. A., Singer, M., \& Susser, I. (2003). Medical anthropology and the world system. Praeger Publishers.

Bode, M. (2011). The transformations of disease in expert and lay medical cultures. Journal of Ayurveda and Integrative Medicine, 2(1), 14-20.

Bode, M., \& Hariramamurthi, G. (2014). Integrating folk healers in india's public health: acceptance, legitimacy and emancipation. EJournal of Indian Medicine, 7, 1-20.

CBS. (2014a). National Population and Housing Census 2011 Social Characteristics Tables (Caste/Ethnicity, Mother Tongue and Second Language). Retrieved from Central Bureau of Statistics website: http://cbs.gov.np/image/ data/Population/District\%20Level\%20Detail\%20Report/ Volume05Part02.pdf

CBS. (2014b). National Population and Housing Census 2011 (Village Development Committee/Municipality) DANG. Retrieved from Central Bureau of Statistics website: http:// cbs.gov.np/image/data/Population/District\%20Level\%20 Detail\%20Report/Volume05Part02.pdf

Dahal, D. R. (2012). Adibasi/Janajati/Indigenous/ Nationalities of Nepal: Socio- Economic Situations and Some Questions on Change and Development. In Contemporary Nepal. B. C. Upreti and Uddhab P. Pyakurel, eds. (pp. 139-150). New Delhi: Kalinga Publications.

Dahit, G. (2008). Research Brief: Inclusion/exclusion of Tharu indigenous knowledge and practices. Kathmandu: Social Inclusion Research Fund (SIRF)/SNV Nepal.

Durkin-Longley, M. (1984). Multiple Therapeutic Use in Urban Nepal. Social Science \& Medicine, 19(4), 867-872.

Gewali, M. B. (2008). Aspects of Traditional medicine in Nepal. Suresh Awale, Ed. Sugitani, Toyama: Institute of Natural medicine, University of Toyama.

Guneratne, A. (2010). Tharu-State Relations in Nepal and India. Himalaya, The Journal of the Association for Nepal and Himalayan Studies, 29(1), 19-28.

Han, G.-S. (2002). The Myth of Medical Pluralism: A Critical Realist Perspective. Sociological Research Online, 6(4). Retrieved from http://www.socresonline.org.uk/6/4/han.html Hyma, B., \& Ramesh, A. (1994). Traditional Medicine: Its Extent and Potential for Incorporation into Modern National Health Systems. In Health and Development. David R. Phillips and Yola Verhasselt, eds. London: Routledge.

Kalpagam, U. (Ed. ). (2012). Ethics, Health and Medicine: Introduction. In Ethics, Health and Medicine: Anthropological Perspectives (pp. 1-33). New Delhi: Manak Publications Pvt. Ltd.

Kleinman, A. (1980). Patients and healers in the context of culture: an exploration of the borderland between anthropology, medicine and psychiatry. University of California Press.

Leslie, C. (1988). Social Research and Health Care Planning in South Asia Part 1. Ancient Science of Life, 8(1), 1-12.

Maiti, S. (2001). Tribal arts and crafts: a study among the tharus of uttar pradesh. Indian Anthropologists, 32(2), 69-74.

McDonaugh, C. (1989). The mythology of the tharu: aspect of cultural identity, in Dang, west Nepal. Kailash Journal of Himalayan Studies, $15(3$ \& 4), 191-204.

Minocha, A. A. (1980). Medical pluralism and health services in india. Social science \& medicine. Part B: Medical Anthropology, 14(4), 217-223.

MoHP. (1996). Rastriya Aayurved Swasthya Niti 2052 [National Ayurveda Health Policy 1996]. Ministry of Health and Population, Department of Ayurveda Government of Nepal.

MoHP. (2012). Swasthya tatha Janasankhya Mantralaya ko Samchhipta Parichaya: Barsik Karyakram Bajet tatha Pragati Bibaran [A Brief Profile of Ministry of Health and Population: Annual Program, Budget and Progress Report]. Ministry of Health and Population, GoN.

MoHP. (2014). Rastriya swasthya Niti 2071 [The National Health Policy 2014]. Ministry of Health and Population, Government of Nepal.

MoHP. (2017). Rastriya Swasthya Niti 2074 [The National Health Policy 2017] First Draft of on New Health Policy submitted by High Level Committee for Internal and Public Discussion. Ministry of Health and Population, Government of Nepal.

Nepal Law Commission. (1988). Ayurveda medical council act, 2045 (1988). Retrieved from http://www.lawcommission. gov.np/en/documents/2015/08/ayurveda-medical-councilact-2045-1988.pdf

NESAC. (1998). Nepal human development report, 1998. Nepal South Asia Center (NESAC).

NFDIN. (2003). National foundation for development of indigenous nationalities: an introduction. National Foundation for Development of Indigenous Nationalities (NFDIN).

NPC. (1980). Sixth five year plan (1980-1985). National Planning Commission, Government of Nepal.

NPC. (1993). Eighth five year plan (1992/93-1996/97). National Planning Commission, Government of Nepal.

NPC. (1997). Ninth Five Year Plan (1996/97-2000/01). National Planning Commission, Government of Nepal.

Oswald, I. H. (1983). Are traditional healers the solution to the failures of primary health care in rural Nepal? Social Science $\&$ Medicine, 17(5), 255-257.

Parker, B. (1988). Ritual Coordination of Medical Pluralism in Highland Nepal: Implication for Policy. Social Science \& Medicine, 27(9), 919-925.

Pigg, S. L. (1996). The Credible and the Credulous: The Question of "Villagers" Beliefs" in Nepal." Cultural Anthropology, 11(2), 160-201.

Pigg, S. L. (1997). Found in Most Traditional Societies: Traditional Medical Practitioners between Culture and Development. In International Development and Social Sciences: Essays on the History and Politics of Knowledge. Frederick Cooper and Randall Packard (pp. 259-290). University of California 
Press.

Pordie, L. (2007). Presentation Ethnographies of "Folk Healing." Indian Anthropologist, 37(1), 1-12.

Prasad, P. N. (2007). Healing in south gujrat: conception, practices and restricted medical pluralism. Indian Anthropologist, Vol. $37(1), 13-28$.

Priya, R. (2012). Ayush and public health: democratic pluralism and quality of health services. In Medical Pluralism in Contemporary India.V. Sujatha and Leena Abraham, eds. (pp. 103-129). Orient Blackswan Pvt. Ltd.

Rajaure, D. (1981a). Tharus of Dang: The people and the social context. Kailash Journal of Himalayan Studies, XVII(3 \& 4), $155-188$

Rajaure, D. (1981b). The Tharu Women of Sukrawar. Tribhuvan University. Center for Economic Development and Administration.

Rajaure, D. (1982). Tharus of Dang: Tharu Religion. Kailash Journal of Himalayan Studies, 9(1), 61-96.

Regmi, R. R. (1999). Dimensions of Nepali Society and Culture. SANN Research Institute.

Schwartz, L. R. (1969). The hierarchy of resort in curative practices: the admiralty islands, melanesia. Journal of Health and Social Behavior, 10(3), 201-209. https://doi. org/10.2307/2948390

Sen, G., Iyer, A., \& George, A. (2007). Systematic hierarchies and systemic failures: Gender and health inequities in Koppal district. Economic \& Political Weekly, 682-690.

Shafey, O. (1997). Medical pluralism among the tharu people of far west nepal: the logic of shamanism at the jungle frontier (ph. D. Dissertation). University of California San Fransisco.

Subedi, B. (2016a). How healthy are we? Narratives of experiential health from a village of Western Nepal. Dhaulagiri Journal of Sociology and Anthropology, 10(1), 123-143.

Subedi, B. (2016b). Medical pluralism: policies and practices in Nepal. In Understanding Nepal in Contemporary Times. Pramod Jaiswal, ed. (pp. 334-363). Synergy Publications.

Subedi, J. (1989). Modern Health Services and Health Care Behavior: A Survey in Kathmandu, Nepal. Journal of Health and Social Behavior, 30(4), 412-420.

Subedi, J. (1992). Primary health care and medical pluralism exemplified in Nepal: a proposal for maximizing health care benefit. Sociological Focus, Special Issue: Health And Health Care in DevelopingCountries, 25(4), 321-328.

Subedi, M. S. (2003). Healer choice in medically pluralistic cultural settings: an overview of Nepali medical pluralism. Occasional Papers in Sociology and Anthropology 8, 128158.

Tamang, A. L., \& Broom, A. (2010). The Practice and Meanings of Spiritual Healing in Nepal. South Asian History and Culture, 1(2), 328-340.

Toffin, G. (2016). Neither statues nor rituals: An analysis of New Religious Movements and Therapists in Nepal. In Religion, Secularism, and Ethnicity in Contemporary Nepal. David Gellner, Sondra L Hausner and Chiara Letizia, (eds) (pp. 115-149). Open University Press.

WHO, \& UNICEF. (1978). Primary health care: report of the international conference on primary health care, alma-ata, ussr, 6-12 september 1978. World Health Organization.

Yazbeck, A. S., \& Peters, D. H. (2003). Health policy research in south asia: building capacity for reform (Health, Nutrition and Population Series). The World Bank.
Bamdev Subedi is a medical anthropologist with an interest in public health issues. He holds an MA in Anthropology from Tribhuvan University, Kathmandu and M.Phil and PhD from Centre of Social Medicine and Community Health, Jawaharlal Nehru University, New Delhi. He has more than a decade of working experience in health and community development programs. His research interests include traditional medicine, medical pluralism and political economy of health.

Email: bamdevsubedi@gmail.com 